\title{
TINGKAT KETERAMPILAN DASAR FUTSAL PADA EKSTRAKURIKULER FUTSAL NIHAYATUL AMAL PURWASARI
}

\author{
Yuga Wibawa Sutiana ${ }^{1}$, Febi Kurniawan ${ }^{2}$, Citra Resita ${ }^{3}$, Qorry Armen \\ Gemael $^{4}$
}

Fakultas Keguruan dan Ilmu Pendidikan, Universitas Singaperbangsa Karawang, Karawang, Indonesia ${ }^{1,2,3,4}$

Yugawibawa10@gmail.com ${ }^{1}$, febi.kurniawan@fkip.unsika.co.id ${ }^{2}$ citra.resita@yahoo.co.id ${ }^{3}$, qorry.gemael@fikes.unsika.ac.id ${ }^{4}$

\begin{abstract}
Abstrak
Penelitian ini dilakukan dengan tujuan untuk mengetahui tingkat keterampilan dasar futsal pada peserta ekstrakurikuler futsal di sekolah Nihayatul Amal Purwasari. Penelitian ini terfokus terhadap keterampilan dasar futsal peserta ekstrakurikuler futsal, yaitu: passing, cotroling, chipping, dribbling, shooting. Dengan uraian di atas penulis menggunakan pendekatan deskriptif kuantitatif dengan metode survei dengan satu variabel tanpa membuat perbandingan dan menghubungkan dengan variable lain. Teknik pengumpulan datanya menggunakan tes dan pengukuran. Pada penelitian ini, mengunakan instrumen "Tes Futsal FIK Jogja" yang sudah di adopsi dengan validasi isi menggunakan validitas muka dan logis kepada para ahli. Hasil penelitian menunjukan peserta yang masuk kategori "sangat baik" sebanyak 0 (nol) orang $(0 \%)$, kategori "baik" sebanyak 5 orang (36\%), kategori "cukup" sebanyak 6 orang (43\%), kategori "kurang baik" sebanyak 1 orang (7\%), kategori "sangat kurang baik" sebanyak 2 orang (14). Berdasarkan hasil penelitian pada peserta ekstrakurikuler futsal sekolah Nihayatul Amal Purwasari, dapat disimpulkan bahwa tingkat keterampilan dasar futsal peserta ekstrakurikuler futsal di Sekolah Nihayatul Amal Purwasari masuk kategori "Cukup" dan hipotesisnya "tidak terbukti", sebab frekuesi peserta ekstrakurikuler sebanyak 6 orang (43\%) yang artinya tingkat keterampilan futsal peserta ekstrakurikuler futsal tersebut berada antara "Baik" dan "Kurang", sedangkan nilai rata-rata sebesar 62,07 terletak pada interval $59<\mathrm{X} \leq 66$.
\end{abstract}

Kata Kunci: Keterampilan dasar futsal, tes dan pengukuran

\section{SKILL LEVEL OF FUTSAL ON EXTRACURRICULAR FUTSAL NIHAYATUL AMAL PURWASARI SCHOOL}

\begin{abstract}
This research was conducted with the aim to find out the basic skills level of futsal on futsal extracurricular participants at Nihayatul Amal Purwasari School. This research focused on the futsal basic skills of futsal extracurricular participants, namely: passing, cotroling, chipping, dribbling, shooting. With the description above the author used a descriptive quantitative approach to the survey method with one variable without making comparisons and connecting with other variables. Data collection techniques using tests and measurements. In this study, using the instrument "FIK Jogja Futsal Test" that has
\end{abstract}


been adopted with content validation using face validity and logic to the experts. The results showed that participants who were in the "very good" category were 0 (zero) people (0\%), the "good" category was 5 people (36\%), the "enough" category were 6 people (43\%), the "not good" category "As many as 1 person (7\%), the category of" very poor "as many as 2 people (14). Based on the results of this research on futsal extracurricular participants at Nihayatul Amal Purwasari School, it could be concluded that the level of futsal basic skills of futsal extracurricular participants at Nihayatul Amal Purwasari School is in the category of "Enough" and the hypothesis is "unproven", because the extracurricular participants are 6 people $(43 \%)$ which means the futsal skill level of futsal extracurricular participants is between "Good" and "Less", while the average value of 62.07 lies at an interval of $59<X \leq 66$.

Keywords: futsal basic skills, tests and measurement.

Correspondence author: Yuga Wibawa Sutiana, Febi Kurniawan, Citra Resita, Qorry Armen Gemael, Universitas Singaperbangsa Karawang, Indonesia. E-Mail: Yugawibawa10@gmail.com

(c) (i) (2)

Jurnal HalamanOlahraga Nusantara licensed under a Creative Commons Attribution-ShareAlike 4.0 International License.

\section{PENDAHULUAN}

Olahraga permainan futsal merupakan olahraga permainan yang mengalami perkembangan yang sangat luar biasa di Indonesia. Hal ini dapat dilihat dari banyaknya kompetisi futsal yang diselenggarakan baik dalam tingkat umum, mahasiswa, maupun pelajar, bahkan sampai ada Liga Futsal Indonesia. Futsal adalah olahraga permainan yang sangat cepat dan dinamis (Irsawanto, 2017). Berbeda sekali dengan sepakbola yang harus memaksimalkan kondisi fisik (Palmizal, Day, \& Murniati 2019). Dari segi lapangan futsal yang relatif kecil hampir tidak ada ruang untuk membuat kesalahan. Kondisi fisik yang prima dibutuhkan siswa untuk bisa maksimal pada ekstrakurikuler (Daryono, 2018). Maka dari itu, diperlukan kerja sama untuk saling mensuport pemain dengan keterampilan-keterampilan dasar kondisi fisik yang sangat baik dan dimiliki oleh setiap pemain, serta melalui timing dan positioning pemain yang tepat akan dapat merebut kembali bola dari lawan.

Menurut Lhaksana (2011) Futsal merupakan olahraga tim, menggunakan kolektifitas tinggi yang akan mengangkat prestasi, siapa yang mencetak gol tidak penting sama sekali, yang terpenting adalah gol yang tercetak. Menurut Kurniawan (2017) "Futsal adalah jenis permainan yang tidak jauh berbeda dengan sepak bola inti permainannya adalah menyepak bola kesana kemari, merebut bola antar pemain, dengan tujuan memasukan bola ke gawang lawan atau mempertahankan gawang sendiri agar tidak kemasukan bola".

Uraian diatas dapat juga dihubungkan dengan permasalahan yang ada di sekolah Nihayatul Amal Purwasari yaitu menurunnya prestasi ekstrakurikuler futsal di sekolah tersebut yang mungkin bisa terjadi karena keterampilan yang 
dimiliki oleh setiap peserta ekstrakurikulernya atau bahkan keterampilan peserta ektrakurikuler sekolah lain yang berkembang sangat cepat. Maka dari itu peneliti bertujuan ingin mengetahui keterampilan dasar futsal yang dimiliki oleh peserta ekstrakurikuler futsal di sekolah Nihayatul Amal Purwasari. Penelitian ini dilakukan dengan tujuan untuk mengetahui tingkat keterampilan dasar futsal pada peserta ekstrakurikuler futsal di sekolah Nihayatul Amal Purwasari. Penelitian ini terfokus terhadap keterampilan dasar futsal peserta ekstrakurikuler futsal, yaitu: passing, controling, chipping, dribbling, shooting.

\section{METODE}

Pendekatan penelitian ini termasuk ke dalam penelitian deskriptif kuantitatif dengan metode survei dengan mengumpulkan data menggunakan tes dan pengukuran. Menurut Sugiyono (2016) metode penelitian kuantitatif adalah metode penelitian yang berlandaskan pada filsapat positipisme, digunakan untuk meneliti pada populasi atau sampel tertentu, pengumpulan data menggunakan instrument penelitian, analisis data bersifat kuantitatif/ statistik, dengan tujuan untuk menguji hipotesis yang telah ditetapkan. Sugiyono (2016). "Metode penelitian deskriptif ini dilakukan untuk mengetahui keberadaan variable mandiri, baik satu variable atau lebih (variable yang berdiri sendiri atau variable bebas) tanpa membuat perbandingan variabel itu sendiri dan mencari hubungan dengan variable lain". "Metode survei ini digunakan untuk mendapatkan data dari tempat tertentu yang alamiah (bukan buatan) tetapi peneliti melakukan perlakuan dalam pengumpulan data, misalnya dengan mengedarkan kuesioner, melakukan test, melakukan wawancara yang tersetruktur dan sebagainya (Sugiyono, 2016)

Populasi dalam penelitian ini adalah peserta ekstrakurikuler futsal di sekolah Nihayatul Amal Purwasari yang berjumlah 14 orang peserta. Dalam penelitian ini peneliti menggunakan jenis sempel yaitu sampling jenuh. Sampling jenuh yaitu teknik penentuan sampel bila semua anggota atau jumlah populasi digunakan sebagai sampel (Sugiyono, 2016). Jadi sampel yang digunakan dalam penelitian ini adalah peneliti menggunakan sampel dengan keseluruhan dari jumlah populasi, atau jumlah seluruh dari peserta ekstrakurikuler futsal di Nihayatul Amal Purwasari yang berjumlah 14 orang peserta. Penelitian dilaksanakan pada Februari 2020.

Teknik pengumpulan data dalam penelitian ini yaitu peneliti memberikan 2 kali kesempatan melakukan tes kepada subjek penelitian dengan menggunakan instrumen "Tes Futsal FIK Jogja (Susworo \& Saryono 2009)" yang sudah di adopsi, uji validitas (Febriayana, 2018) dan disesuaikan dengan tempat pengambilan data (lapangan futsal sekolah Nihayatul Amal Purwasari) yang terdiri dari 4 (empat) item tes yaitu: passing, controlling, dribbling, shooting., kemudian dapat di peroleh dan di ambil data dari peserta penelitian dengan dan memperoleh data dalam satuan waktu (detik/ second). Dari 2 kali kesempatan yang diberikan untuk objek penelitian melakukan tes di ambil waktu yang paling bagus yaitu waktu paling cepat.

Penelitian ini menggunakan teknik analisis data statistik deskriptif. Statistik deskriptif adalah bagian dari statistik yang digunakan untuk menganalisis 
data dengan cara mendeskripsikan atau menggambarkan data yang telah terkumpul sebagaimana adanya tanpa bermaksud membuat kesimpulan yang berlaku untuk umum atau generalisasi (Sugiyono, 2016). Menurut Sudijono (2012) untuk mendesripsikannya dengan menentukan kategori dan kategori yang digunakan tersebut adalah rumus statistik beradasarkan mean dan setandar deviasi. Hasil penelitian ini dituangkan dalam 5 kategori A, B, C, D, E yang dimodifikasi menjadi sangat baik, baik, cukup, kurang baik dan sangat kurang baik. Pengkategorian tersebut dapat dijabarkan sebagai berikut:

Tabel 1. Penjabaran Rumus Pengkategorian dari Hasil Tes dan Keterampilan Dasar Futsal

\begin{tabular}{lc}
\hline & Sangat Baik \\
Mean + 1,5 SD & Baik \\
Mean + 0,5 SD & Cukup \\
Mean - 0,5 SD & Kurang Baik \\
Mean - 1,5 SD & sangat kurang Baik \\
\hline
\end{tabular}

Pengkategorian berdasarkan penjabaran dari rumus Sudijono yang ada dan sipaparkan di atas harus dibalik atau di-invers terlebih dahulu agar dapat digunakan dalam penelitian ini dan akan dijadikan sebagai pedoman/ patokan/ acuan dalam pengelompokan hasil penelitian ini, karena pengelompokan dari rumus (Sudijono 2012) menunjukan hasil yang lebih baik jika nilai yang di dapat oleh objek penelitian semakin besar, sedangkan pengelompokan hasil penelitian ini menunjukan hasil yang lebih baik jika objek penelitian mendapatkan nilai yang semakin kecil.

Tabel 2. Rumus Pengelompokan Hasil Tes dan Keterampilan Dasar Futsal

\begin{tabular}{ccc}
\hline 1 & $\mathrm{X} \leq \mathrm{M}-1,5 \mathrm{SD}$ & Sangat Baik \\
2 & $\mathrm{M}-1,5 \mathrm{SD}<\mathrm{X} \leq \mathrm{M}-0,5 \mathrm{SD}$ & Baik \\
3 & $\mathrm{M}-0,5 \mathrm{SD}<\mathrm{X} \leq \mathrm{M}+0,5 \mathrm{SD}$ & Cukup \\
4 & $\mathrm{M}+0,5 \mathrm{SD}<\mathrm{X} \leq \mathrm{M}+1,5 \mathrm{SD}$ & Kurang Baik \\
5 & $\mathrm{X} \geq \mathrm{M}+1,5 \mathrm{SD}$ & Sangat Kurang Baik \\
\hline
\end{tabular}

Tingkat keterampian dasar bermain futsal yang sudah dikategorikan sesuai dengan rumus di atas kemudian dilakukan penghitungan atau pengelompokan frekuensi setiap kategori yang akan disajikan dalam bentuk presentase dan setelah selesai di buat dan dijadikan ke dalam diagram. Rumus yang digunakan untuk mengelompokan hasil dari tingkat keterampilan dasar futsal dengan presentase adalah:

$$
\mathrm{P}=\frac{F}{N} \times 100 \%
$$

Keterangan : $\quad \mathrm{P}=$ presentasi yang dicari 


$$
\begin{aligned}
& \mathrm{F}=\text { frekuensi } \\
& \mathrm{N}=\text { jumlah responden }
\end{aligned}
$$

\section{HASIL DAN PEMBAHASAN}

Pada peserta ekstrakurikuler futsal yang hasilnya masuk dalam kategori "baik" dan "cukup" ini, pada saat melakukan tes untuk pengambilan datanya peserta tersebut melakukannya dengan serius. Sedangkan peserta yang mendapatkan hasil "kurang" dan "sangat kurang" di dominasi oleh peserta yang kurang serius dalam melakukan tes tersebut dan memiliki jam bermain yang lebih sedikit dalam mengikuti kompetisi atau kejuaraan, sehingga dapat mempengaruhi kesiapan peserta dalam melakukan test tersebut. Hasil penelitian secara keseluruhan dapat disimpulkan bahwa, tingkat keterampilan dasar futsal pada peserta ekstrakurikuler futsal di Sekolah Nihayatul Amal Purwasari dinyatakan "Cukup" yaitu dengan frekuesi peserta ekstrakurikuler sebanyak 6 orang (43\%). Artinya tingkat keterampilan futsal peserta ekstrakurikuler futsal tersebut berada antara "Baik" dan "Kurang", sedangkan nilai rata-ratanya sebesar 62,07 terletak pada interval $59<\mathrm{X} \leq 66$.

Tabel 3. Distribusi Frekuensi Kelas Interval dan Kategori Tingkat Keterampilan Dasar Futsal Peserta yang Mengikuti Kegiatan Ekstrakurikuler Futsal di Sekolah Nihayatul Amal Purwasari

\begin{tabular}{cccc}
\hline Kelas Interval & Kategori & Frekuensi & Persentase \\
\hline $\mathrm{X} \leq 51,54$ & Sangat Baik & 0 & $0 \%$ \\
$51,54<\mathrm{X} \leq 58,56$ & Baik & 5 & $36 \%$ \\
$58,56<\mathrm{X} \leq 65,58$ & Cukup & 6 & $43 \%$ \\
$65,58<\mathrm{X} \leq 72,60$ & Kurang Baik & 1 & $7 \%$ \\
$\mathrm{X} \geq 72,60$ & Sangat Kurang Baik & 2 & $14 \%$ \\
Jumlah & & 14 & $100 \%$ \\
\hline
\end{tabular}

Berdasarkan tabel di atas tingkat keterampilan dasar futsal peserta ekstrakurikuler futsal Sekolah Nihayatul Amal Purwasari kemudian di kategorikan menjadi 5 kategori dengan rumus penjabaran. Data distribusi frekuensi menunjukan peserta ekstrakurikuler yang masuk kategori "Sangat Baik" sebanyak 0 (nol) tidak ada (0\%), kategori "Baik" sebanyak 5 orang (36\%), kategori "Cukup" sebanyak 6 orang (43\%), kategori "kurang baik" sebanyak 1 orang (7\%), dan kategori "sangat kurang baik" sebanyak 2 orang (14\%). 


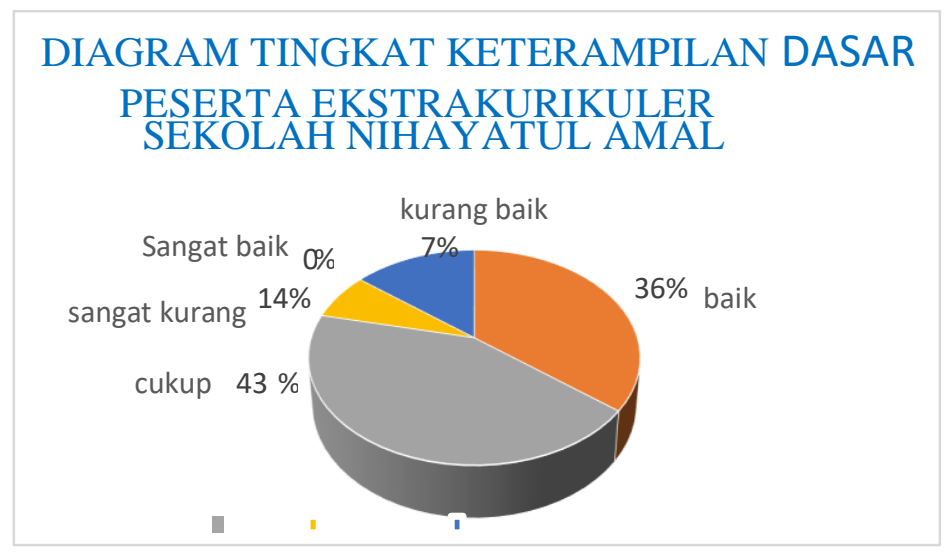

Gambar 1.Diagram Tingkat Keterampilan Dasar Futsal Peserta Ekstrakurikuler Futsal di Sekolah Nihayatul Amal Purwasari

\section{KESIMPULAN}

Dari uraian diatas dapat diambil kesimpulan dan menjawab masalah yang di angkat bahwa menurunnya prestasi ekstrakurikuler futsal di sekolah Nihayatul Amal Purwasari tidak sepenuhnya pengaruh dari keterampilan yang dimiliki oleh peserta ekstrakurikuler. Sebab berdasarkan hasil penelitian pada peserta ekstrakurikuler futsal sekolah Nihayatul Amal Purwasari masuk kategori "Cukup" dan hipotesisnya "tidak terbukti", artinya untuk keterampilan dasar peserta ekstrakurikuler futsal sekolah Nihayatul Amal Purwasari sudah "cukup" untuk dapat bermain futsal.

\section{DAFTAR PUSTAKA}

Daryono, Daryono. 2018. "Survei tingkat ketrampilan teknik dasar sepakbola dan kemampuan fisik siswa peserta ekstrakulikuler sepakbola di smp negeri 4 ungaran kabupaten semarang tahun ajaran 2010/2011." Jurnal Dosen Universitas PGRI Palembang.

Febriayana, Y. 2018. "Uji Validitas Dan Reliabiltas Instrumen Penelitian Kuantitatif." Jurnal Ilmu Kependidikan 7(1):17-23.

IRSAWANTO, ZUHDII. 2017. "Tingkat Keterampilan Bermain Futsal Peserta Ekstrakurikuler Futsaldi SMP Negeri 3 Gresik." Jurnal Prestasi Olahraga 1(1).

Kurniawan, Febi. 2017. "Futsal Basic Skills.” Bekasi: Cakrawa Cendikia.

Lhaksana, Justinus. 2011. "Taktik Dan Strategi Futsal." Depok: Be Champion (Penebar Swadaya Group).

Palmizal, Palmizal, Wawan Junresti Day, and Sri Murniati. 2019. “Tinjauan Kondisi Fisik Atlet Sepakbola Kabupaten Kerinci Dalam Rangka 
Yuga Wibawa Sutiana, Febi Kurniawan, Citra Resita, Qorry Armen Gemael (2020)

Tingkat Keterampilan Dasar Futsal Pada Ekstrakurikuler Futsal Nihyatul Amal Purwasari

Persiapan Mengikuti Porprov Xxii Bungo Tebo 2018." Halaman Olahraga Nusantara (Jurnal Ilmu Keolahragaan) 2(1):72-78.

Sudijono, Anas. 2012. "Pengantar Statistik.” Raja Grafindo Persada, Jakarta.

Sugiyono. 2016. "Metode Penelitian Pendidikan (Pendekatan Kuantitatif,Kualitatif, Dan R\&D).” Jakarta: Rajagrafindo Persada.

Susworo, Agus DM, and Yudanto Saryono. 2009. "Tes Keterampilan Dasar Bermain Futsal.” Jurnal IPTEK Olahraga 11(2). 